\title{
Studien über die bluteiweiss= und kolloid-osmoregulierende Tätigkeit der Leber.
}

\author{
I. Mitteilung: Über den Eiweissgehalt und den kolloid-osmotischen \\ Druck des Zu- und abströmenden Blutes der Leber, mit besonderer \\ Berücksichtigung ihrer Veränderungen nach Eiweissverlust \\ durch Aderlass und Plasmaphäresis. Versuch \\ an normalen Kaninchen.
}

Von

Hisashi Yasuda.

(妿田 久)

(Aus der Medizinischen Klinik von Prof. Dr. T. Kato, Tohoku-Reichsuniversität zu Sendai.)

Es ist seit langem eine wohlbekannte Tatsache, dass beim Stoffaustausch zwischen Blut und Gewebe der kolloid-osmotische Druck des Blutes eine wichtige Rolle spielt, und zur Aufrechterhaltung seiner optimalen Verhältnisse müssen die Eiweisskörper des Blutes sowohl quantitativ wie auch qualitativ fein und kunstgerecht reguliert werden. Und als osmoregulatorische Organe kommt in erster Linie die Leber in Betracht. Dieses Organ stellt das Zentralorgan des Stofiwechsels dar, steht zum Verdauungstraktus in innigster Beziehung und nimmt verschiedene Substanzen, welche durch die Pfortader resorbiert werden, zuvörderst in sich auf. Im Zusammenhang. damit ist es leicht verständlich, dass die Leber für die quantitative und qualitative Regulierung des Bluteiweisses, also für die Osmoregulation des Blutes eine wichtige Rolle spielt.

Seitdem $P f l u ̈$ g e ${ }^{1)}$ als erster darauf hingewiesen hat, dass die Leber die Vorratskammer des Eiweisses sei, haben sich viele Forscher mit diesem Problem beschäftigt; so hat z.B. Seitz ${ }^{2)}$ an Hühnern und Enten das Gewicht und die Eiweiss-N-Menge der Leber sowohl bei eiweissreicher Fütterung wie auch im Hunger vergleichend bestimmt und kam zum Ergebnisse, dass oben erwähnte Werte bei eiweissreicher Fütterung ca. das doppelte derselben im Hunger er-

1) Pflüger, Arch. f.d. ges. Physiol., 1903, 96, 381.

2) Seitz, Ibid., 1906, 111, 309. 
reichten; $R$ ea $\mathrm{ch}^{3)}$ sah bei der Durchströmung der überlebenden Leber mit Jodeiweisslösung, dass das Jodeiweiss in der Leber aufgespeichert war. Gru nd $\mathrm{d}^{4)}$ und $\mathrm{F}$ is c her $\mathrm{r}^{5)}$ haben auch dasselbe Experiment wie Seit $\mathrm{z}^{2}$ an Hunden und Hühnern durchgeführt und fanden, dass die Leber in einem Zustand der Eiweissmast mehr Eiweiss gegenüber der Niere und Muskulatur aufnahm, während sie im Hunger mehr Eiweiss verlor. Junkersdor $f^{6)}$ fand beim Hund bei Eiweissfütterung die Zunahme des Lebergewichtes und hat daraus geschlossen, dass die Leber auf den Eiweissstoff wechsel physiologisch eine regulierende Funktion ausübe.

So stimmen oben genannte Autoren alle der Meinung von Pflüg er $r^{1)}$ bei. Die Pflügers Ansicht ist aber auch durch Untersuchungen von vielen Autoren, wie Berg, ${ }^{7}$ Berg und Cahn-Bonner, ${ }^{8)}$ Stübel, ${ }^{9}$ ) Rothmann, ${ }^{10}$ ) Warasili ${ }^{11)} \mathrm{Paschkis^{12 }}$ u.a. histologisch bestätigt worden; namentlich haben drei letztgenannte Forscher weiterhin auch die Mobilisation des Reserveeiweisses der Leber nachgewiesen.

Durch obige Untersuchungen von verschiedenen Autoren ist es nunmehr festgestellt worden, dass die Leber der Stapelplatz des Eiweisses ist, und des weiteren ist von einer Reihe Forschern, wie Ja c ob y, $\left.{ }^{13}\right)$ Doy on und $\mathrm{K}$ a reff, ${ }^{14}$ ) Whipple and Hurwitz, ${ }^{15)}$ Foster und Whipple, ${ }^{16)} \mathrm{Ozawa},{ }^{17}$ ) Tanaka, ${ }^{18}$ ) Senshu, $\left.{ }^{19}\right) \mathrm{Henriques}$ und $\mathrm{Klausen},{ }^{20} \mathrm{Hand}{ }^{21)}$ u.a. klargestellt worden, dass die Leber einen bestimmten Einfluss auf die Bluteiweissfraktionen hat.

Demnächst wollen wir einen Rückblick auf Untersuchung über den Einfluss der Leber auf den kolloid-osmotischen Druck des Blutes (im folgenden abgekürzt: k.o.D.) werfen.

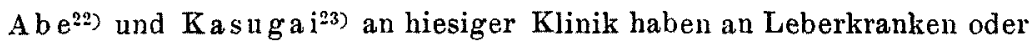

3) Reach, Bioch. Ztschr., 1909, 16, 357.

4) Grund, Ztsohr. f. Biol., 1910, 54, 173.

5) Fis chler, Physiologie und Pathologie der Leber, 2. Aufl., Berlin, 1925, 113.

6) Junkersdorf, Arch. f.d. ges. Physiol., 1921, 186, 238.

7) Berg, Bioch. Ztschr, 1914, 61, 428.

8) Berg u. Cahn-Bonner, Ibid., 1914,61,434.

9) Stübel, Arch. f.d. ges. Physiol., 1920, 185, 74.

10) Rothmann, Ztschr. f.d.ges. exp. Med., 1924, 40, 253.

11) Wa rasi, Ibid., $1929,66,436$.

12) Paschkis, Klin. Wochenschr., 1929, 1293.

13) Jacoby, Ztschr. f. physiol. Chem., 1900, 30, 149.

14) Doyon u. Kareff, C.r. Soc. Biol., 1905, 58, 444.

15) Whipple u. Hurwitz, Journ. Exp. Med., 1911, 13, 136.

16) Foster u. Whip ple, Amer. Journ. Physiol., 1921-22, 58, 407.

17) Ozawa, Fukuoka Ikadaigaku Zasshi, 1926, 19, 591.

18) T a n a ka, Ibid., 1928, 21, 948.

19) Senshu, Journ. Biochem., 1930, 11, 47.

20) Henriques u. Klausen, Biochem. Ztschr., 1932, 254, 414.

21) Hand, Arch. Intern. Med., 1934, 54, 215.

22) A be, Tohoku Journ. Exp. Med., 1931, 17, 412.

23) Kasuga i, rbid., 1935, 27, 505 . 
experimentell lebergeschädigten Hunden eine Senkung des k.o.D. des Blutes nachgewiesen. Fukuhara ${ }^{24}$ ) hat an Kaninchen mit geschädigter Leber beobachtet, dass nach erfolgter Plasmaphäresis die Wiederherstellung des k.o.D. und Bluteiweisses auf Anfangswerte gegenüber der Norm sehr mangelhaft erfolgt.

Durch oben angeführte, von einer Reihe Autoren nach verschiedenen Richtungen hin ausgeführte Untersuchungen unterliegt heute mehr keinem Zweifel, dass die Leber das Bluteiweiss zu regulieren vermag, mithin auch bei Aufrechterhaltung des k.o.D. des Blutes eine wichtige Rolle spielt. Nichtdestoweniger liegen bis dahin recht spärlich Untersuchungen vor, in denen man, um über die Frage, ob die Leber in der Tat ihr Reserveeiweiss nach Bedarf zu mobilisieren vermöge, oder wenn dies der Fall wäre, inwieweit osmoaktive Eiweissstoffe die Leber abgabe, ins klare zu kommen, direkt am der Leber ent- und zuströmenden Blut dessen Eiweiss und k. o. D. unter verschiedenen Bedingungen bestimmt hat.

Nenerdings hat Horikawa ${ }^{25}$ an hiesiger Klinik bei der Applikation der ultraakustischen Schallwellen auf die Kaninchenleber, Miur ${ }^{26)}$ bei progressiver Sauerstoff verdünnung nachgewissen, dass bei Kaninchen die Senkung des k. o. D. im Lebervenenblut geringer als im Pfortader- und arterieller Blut ist.

In vorliegendem Versuch wurden unter Anwendung von gesunden Kaninchen an drei Blutarten, nämlich am aus der Leber ausströmenden Lebervenenblut und am in die Leber einströmenden Blut, also am Pfortaderblut sowie als Kontrolle am Carotisblut das Bluteiweiss und den k.o.D. bestimmt und darauf gefahndet, welche Unterschiede zwischen derartigen Werten in drei Blutarten bestehen; alsdann in verschiedene Versuchsreihen, in denen durch einmalige bzw. wiederholte Blutentnahmen oder durch Plasmaphäresis Verluste des Bluteiweisses eintraten, wurden an den oben erwähnten drei Blutarten Veränderungen des Eiweisses und k.o.D. ermittelt. In den anderen Versuchsreihen wurden weiterhin auch unter verschiedentlichen pathologischen Verhältnissen Veränderungen der obigen Werte in drei Blutarten durch Bluteiweissverluste verfolgt, damit man sich ein präzises Bild darüber, welche Rolle die Leber unter physiologischen und pathologischen Bedingungen hinsichtlich der Regulation des Bluteiweisses und dessen k.o.D. bei Bluteiweissverlusten spielt, ge-

24) Fukuhara, Tohokn Journ. Exp. Med., 1937, 30, 506.

25) Horikawa, Ibid, 1936, 28, 257.

26) Miura, Ibid, $1936,30,49$. 
winnen könnte. Es seien hier an normalen Kaninchen ausgeführte Versuche angeführt.

Versuchsmethode: Als Versuchsmaterial standen gesunde Kaninchen, welche 12 Stunden lang gehungert hatten, zur Verfügung.

Jedes Versuchstier wurde auf den zuvor elektrisch passend angewärmten Tierhalter in der Rückenlage gefesselt, durch Injektion von $4 \mathrm{ccm}$ einer $25 \%$ igen Urethanlösung pro kg Körpergewicht narkotisiert. Zunächst wurde die A. carotis auf der einen Seite blossgelegt, worin die Kanüle eingeführt und die behufs beliebiger Entnahme arteriellen Blutes mit einer Klemme gefasst wurde. Nachdem dann die Bauchdecke an der Medianlinie entlang aufgeschnitten worden war, wurde nach dem Verfahren von Kimura und $\mathrm{Kato}_{\mathrm{o}^{2 i}}$ zwecks zeitweiser Unterbrechung des Blutstroms in der V. cava inferior eine feine Pferdhaarschlinge dicht unterhalb der Leber an ehen genannter Vene angelagt. Demnächst trennte man die Leber, ohne den Druck darauf auszuüben, vorsichtig von dem $Z$ werchfell, schnitt das daz wischen gespannte Ligamentum ab und legte Gaze, welche mit der auf die Körpertemperatur erwärmten Ringerlösung getränkt wurde, ein, damit die Leber bei der Entnahme des Lebervenenblutes nicht verletzt würde. Die oben erwähnte Prozedur wurde mög. lichst schnell vollendet, die Bauchdecke wurde mit einem mit körperwarmer Ringerlösung getränkten Tuch bedeckt, welches durch elektrische Heizvorrichtung, die sich oben in einem Abstand von ca. $20 \mathrm{~cm}$ befand, erwärmt und so vor der Abkühllung geschützt wurde. Um sonst Einflüsse der Operation möglichst zu vermeiden, wurde die Blutentnahme erst nach zweistündigem Ruhiglassen der Versuchstiere vorgenommen.

Zuvörderst wurde das arterielle Blut durch die in die A. carotis eingeführte Kanüle entnommen, alsdann das Pfortaderblut mittels der Pravatz'schen Spritze durch Punktion des Pfortaderstammes entnommen, die dabei verletzte Gefässwand wurde unter Vermeidung der Stauung des Blutstromes mit einer kleinen Klemme in möglichst kleinem Umfang gefasst. Zuletzt bei der Entnahme des Lebervenenblutes ging man so vor, dass man den Blutstrom in der V. cava inferior, wie oben geschildert, dicht unterhalb der Leber unterbrach und dann im subphrenischen Raum in der Nähe der Eintrittsstelle der V. hepatica in die V. cava inferior durch Punktion Blut entnahm und gleich darauf die Blutzufuhr zur V. cava inferior wiederherstellte. Gegen die Blutung aus der Punktionsstelle ist hierbei auch ohne Nachbehandlung nichts gefährliches zu befürchten.

Auf obige Weise wurden aus dreierlei Blutgefässen, also aus A. carotis, V. portae und V. hepatica je 1, $7 \mathrm{ccm}$ Blut entnommen. Der Hämoglobingehalt des entnommenen Blutes wurde mittels des'Fleischl-Mieschers Hämoglobinometers, der Serumei weissgehalt mit dem Pulf rich'schen Eintauchrefraktometer, der k.o.D. nach der Methode von Krogh und Nakaza wa $a^{28)}$ bestimmt.

27) Ki imura u. Ka to, Tohoku Journ. Exp. Med., 1933, 21, 298.

28) Trogh u. Nakazawa, Biochem. Ztschr., 1927, 188, 241. 
I. Der Eiweissgehalt und der k. o. D. des Lebervenen-, Pfortader- und Carotisblutes bei normalen Kaninchen.

Es kommt hierbei zur Anstellung eines besseren Vergleichs mit den nachfolgenden Untersuchungsresultaten in erster Linie darauf an, zuvor an zahlreichen Kaninchen Klarheit darüber zu verschaffen, wieviel grossen Eiweissgehalt und wieviel hohen kolloid-osmotischen Druck das Lebervenen-, Pfortader- und Carotisblut unter normalen Verhältnissen aufweisen. Auf der Tab. 1 sind an 30 normalen Fällen ausgeführte Bestimmungen zusammengestellt.

Nach dem Hämoglobingehalt beurteilt, besteht $\mathrm{z}$ wischen den drei Blutarten kein Unterschied hinsichtlich der Blutkonzentration.

Was den Eiweissgehalt des Blutes anbelangt, so zeigt er entgegen dem Hämoglobin, Uuterschiede zwischen drei Blutarten. Abgesehen von einigen Fällen, zeigt das Pfortaderblut den grössten Eiweissgehalt, demnächst kommt das Carotisblut; die Werte dieser beiden Blutarten liegen miteinander verhältnismässig nahe. Zwischen dem Eiweissgehalt des Pfortaderblutes und des Leberveneblutes besteht indessen eine beinahe konstante Differenz. Mit Ausnahme von 4 (Versuch 22, 26, 28 und 30) unter 30 Versuchen, ist der Eiweissgehalt des Lebervenenblutes in den übrigen 26 Versuchen stets mehr oder weniger geringer als der des Pfortaderblutes; insbesondere in 11 Versuchen (Versuch 3, 6, 8, 9, 10,12, 19, 20, 23, 27 und 29) von diesen 26 Versuchen tritt diese Differenz am ausgesprochsten hervor. In 4 Ausnahmsfällen ist der Eiweissgehalt im Pfortader- und Lebervenenblut entweder gleichgross (Versuch 22), oder umgekehrt im Lebervenenblut um ein geringes grösser. Wenn man die Werte aus $30 \mathrm{Ver}-$ suchen in den Durchschnittswert umrechnet, so beträgt der Eiweissgehalt im Lebervenenblut 5,86 (7,18-5,07) \%, im Pfortaderblut 6,02 $(7,42-5,18) \%$, und endlich im Carotisblut 5,99 $(7,22-5,16) \%$.

Aus obigen Ergebnissen stellt es sich heraus, dass bei normalen Kaninchen der Eiweissgehalt im allgemeinen im Lebervenenblut kleiner als im Pfortaderblut ist.

K.o.D. zeigt, ausgenomthen einige Fälle, in Pfortaderblut den höchsten Wert, im Carotisblut den weniger hohen Wert und im Lebervenenblut den niedrigsten Wert. Den Durchschnittswerten nach beurteilt, beträgt der k.o.D. des Lebervenenblutes $260(341-215) \mathrm{mm}$ $\mathrm{H}_{2} \mathrm{O}$, der des Pfortaderblutes $276(362-235) \mathrm{mm} \mathrm{H}_{2} \mathrm{O}$ und der des Carotisblutes $271(344-231) \mathrm{mm} \mathrm{H}_{2} \mathrm{O}$. 


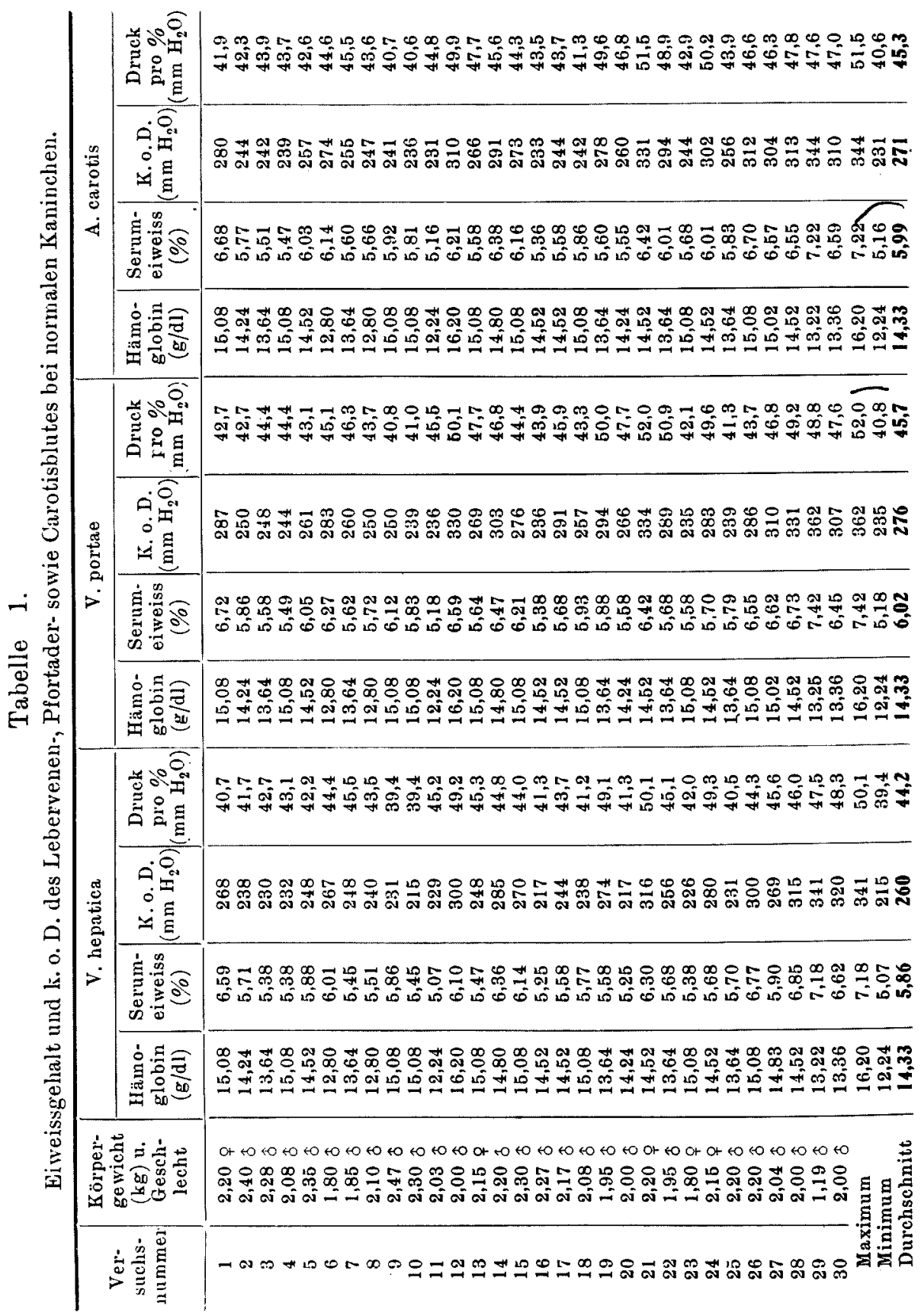


K.o.D. für 1\% Eiweiss (im folgenden abgekürzt: Druck pro \%) liegt im Lebervenenblut bei $44,2(50,1-39,4) \mathrm{mm} \mathrm{H}_{2} \mathrm{O}$, in Pfortaderblut bei $45,7(52,0-40,8) \mathrm{mm} \mathrm{H}_{2} \mathrm{O}$ und im Carotisblut bei $45,3(51,5-$ $40,6) \mathrm{mm} \mathrm{H}_{2} \mathrm{O}$. Ebenso wie k.o.D. kann hier also auch im Pfortaderblut der höchste Wert, im Lebervenenblut der niedrigste Wert ermittelt werden.

$\mathrm{A}$ bd erhalden und L ond o $\mathrm{n}^{29}$ ) haben Hunden mit Eck-Fistel Eiweiss per os zugeführt und da hierbei keine krankhafte Erscheinung auftrat, glauben genannte Autoren annehmen zu dürfen, dass das abgebante Eiweiss in der Darmwand resorbiert und hier assimiliert werde, wobei wahrscheinlich ein Eiweisskörper wie das Albumin entstehen könne. Se hindera $\mathrm{a}^{30}$ nimmt an, dass Eiweiss, welches im Darm zum Körpereiweiss resynthetisiert worden ist, allmählich in die Blutbahn transportiert werde.

Die in meinem obigen Versuch festgestellte Tatsache, dass in der Mehrzahl der Fälle der Eiweissgehalt, der k.o.D. und Druck pro \% des Pfortaderblutes relativ höhere Werte aufweisen, dürfte höchstwahrscheinlich darauf zurückzuführen sein, dass das aus dem Dam resorbierte Eiweiss in der Darmwand zu verhältnismässig kleinmolekulären Eiweissteilchen wie Albumin aufgebildet und in die Pfortader befördert wird.

Es erhebt sich die Frage: Woher kommt es, dass, obwohl die Leber ihr Blut vorwiegend vom Pfortaderblut bezieht, der Eiweissgehalt des Lebervenenblutes den kleineren Wert als der des erstgenannten Blutes aufweist? Es ist dies offenbar ein Beweis dafür, dass der Leber die Eiweiss aufspeichernde Funktion zukommt, und die Pflügers ${ }^{1)}$ Ansicht, die Leber sei die Vorratskammer von Eiweiss, ist damit erwiesen worden. Der Umstand, dass der Druck pro \% des Lebervenenblutes den niedrigsten Wert aufweist, deutet offensichtlich darauf hin, dass die molekuläre Grösse des aus der Leber ausströmenden Bluteiweisses gegenüber demselben der anderen zwei Blutarten nach grobmolekulärer Seite hin verschoben ist.

Dieser Befund stimmt gut überein mit Resultaten von $T$ a naka ${ }^{18}{ }^{18}$ welcher hat bei Hunden nachgewiesen, dass im Hunger das Lebervenenblut im Vergleich zum Pfortaderblut Globulinvermehrung und Albuminverminderung darbietet und von Field, Leigh, Hein und Drinker, ${ }^{31)}$ denen zufolge bei Hunden der osmotische Druck per Gramm und Al/Gl Quotient der Leberlymphe gegenüber den entsprechenden Grössen des Blutserums und der Lymphe in anderen Körperregionen minimale Werte aufweisen.

29) A bderhalden u. London, Ztschr. f. physiol. Chem., 1907, 54, 80.

30) Schindera, Dtseh. Arch. f. klin. Med., 1924, 144, 113.

31) Field, Leigh, Hein u. Drinker, Amer. Journ. Physiol, 1934-35, 110, 174. 
Kurzum, es scheint jedenfalls festzustehen, dass die Leber im normalen Zustand einerseits von der Pfortader her zugeführte Eiwcissstoffe in sich aufspeichert, anderseits aber relativ grossmolekuläre Eiweissteilchen an den allgemeinen Kreislauf abgibt.

II. Veränderungen des Eiweisses und des k. o. D. des Lebervenen-, Pfortader-und Carotisblutes nach einmaligen und wiederholten Blutentnahmen.

Wenn die Tatsache, dass die Leber ein Depotorgan des Bluteiweisses ist, mit voller Sicherheit erwiesen ist, sollte die Leber dort, wo der Organismus durch Blutentnahme einen Teil seines Bluteiweisses

Tabelle

Veränderungen des Eiweissgehalts und k. o. D. des Lebervenen-,

\begin{tabular}{|c|c|c|c|c|c|c|c|c|c|c|c|c|}
\hline \multirow{3}{*}{ 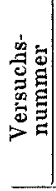 } & \multirow{3}{*}{ 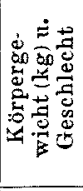 } & \multirow{3}{*}{$\begin{array}{c}\text { Zeit d. } \\
\text { Blutentnahme }\end{array}$} & \multicolumn{8}{|c|}{ V. hepatica } & & \\
\hline & & & \multicolumn{2}{|c|}{$\begin{array}{l}\text { Hämo- } \\
\text { globin }\end{array}$} & \multicolumn{2}{|c|}{$\begin{array}{l}\text { Serum- } \\
\text { eiweiss }\end{array}$} & \multicolumn{2}{|c|}{ K. o. D. } & \multicolumn{2}{|c|}{$\begin{array}{c}\text { Druck pro } \\
\%\end{array}$} & \multicolumn{2}{|c|}{$\begin{array}{l}\text { Fämo- } \\
\text { globin }\end{array}$} \\
\hline & & & $(\mathrm{g} / \mathrm{dl})$ & $\mid \begin{array}{l}\text { Ditf. } \\
\text { in } \%\end{array}$ & $(\%)$ & $\begin{array}{l}\text { Dift. } \\
\text { in } \%\end{array}$ & $\left(\begin{array}{l}\mathrm{mm} \\
\mathrm{H}_{2} \mathrm{O}\end{array}\right)$ & $\begin{array}{l}\text { Ditf. } \\
\text { in } \% \\
\end{array}$ & $\left(\begin{array}{c}m m \\
H_{2} \mathrm{O}\end{array}\right)$ & $\begin{array}{c}\text { Ditt. } \\
\text { in } \%\end{array}$ & $(\mathrm{~g} / \mathrm{dl})$ & \begin{tabular}{|l|} 
Ditf. \\
in $\%$ \\
\end{tabular} \\
\hline 1 & $\begin{array}{c}2,16 \\
\delta\end{array}$ & $\begin{array}{l}\text { I. Blutprobe } \\
\text { II. Blutprobe } \\
\text { (nach 15') }\end{array}$ & $\begin{array}{l}13,94 \\
13,64\end{array}$ & $-2,1$ & $\begin{array}{l}5,51 \\
5,32\end{array}$ & $-3,4$ & $\begin{array}{l}240 \\
235\end{array}$ & $-2,1$ & $\begin{array}{l}43,5 \\
44,2\end{array}$ & $+1,6$ & $\begin{array}{l}13,94 \\
13,64\end{array}$ & $-2,1$ \\
\hline 2 & $\begin{array}{c}1.98 \\
0\end{array}$ & $\begin{array}{r}\text { I. Blatprobe } \\
\text { II. Blutprobe } \\
\text { (uach 15') }\end{array}$ & $\left|\begin{array}{l}14,24 \\
13,94\end{array}\right|$ & $-2,1$ & $\begin{array}{l}5,68 \\
5,32\end{array} \mid$ & $-6,3$ & $\begin{array}{l}248 \\
232\end{array}$ & $-6,4$ & $\begin{array}{l}43,7 \\
43,6\end{array}$ & $-0,2$ & \begin{tabular}{|l|}
14,24 \\
13,94
\end{tabular} & $-2,1$ \\
\hline 3 & $\begin{array}{c}2,14 \\
\hat{\jmath}\end{array}$ & $\begin{array}{r}\text { I. Blutprobe } \\
\text { II. Blutprobe } \\
\text { (nach 15') }\end{array}$ & $\begin{array}{l}15,58 \\
15,08\end{array}$ & $-3,2$ & $\begin{array}{l}6,27 \\
5,83\end{array}$ & $-7,0$ & $\begin{array}{l}251 \\
248\end{array}$ & $-1,2$ & $\begin{array}{l}40,0 \\
42,5\end{array}$ & $+6,2$ & $\begin{array}{l}15,58 \\
15,08\end{array}$ & $-3,2$ \\
\hline 4 & $\begin{array}{c}2,07 \\
\delta\end{array}$ & $\begin{array}{r}\text { I. Blutprobe } \\
\text { II. Blutprobe } \\
\text { (nach 15') }\end{array}$ & $\begin{array}{l}15,27 \\
14,24\end{array}$ & $-6,7$ & $\begin{array}{l}5,79 \\
5,38\end{array}$ & $-7,1$ & $\begin{array}{l}232 \\
217\end{array}$ & $-6,5$ & $\begin{array}{l}40,1 \\
40,3\end{array}$ & $+0,5$ & $\begin{array}{l}15,27 \\
14,24\end{array}$ & $-6,7$ \\
\hline$\tilde{\mathbf{5}}$ & $\begin{array}{c}2,46 \\
9\end{array}$ & $\begin{array}{l}\text { I. Blutprobe } \\
\text { II. Blutprobe } \\
\left.\text { (nach } 15^{\prime}\right)\end{array}$ & $\begin{array}{l}14,80 \\
13,94\end{array} \mid$ & $-5,8$ & $\begin{array}{l}6,25 \\
6,01\end{array}$ & $-2,2$ & $\begin{array}{l}279 \\
281\end{array}$ & $+0,7$ & $\begin{array}{l}44,6 \\
46,7\end{array}$ & $+4,7$ & $\begin{array}{l}14,80 \\
13,94\end{array}$ & $-5,8$ \\
\hline 6 & $\begin{array}{c}2,20 \\
+\end{array}$ & $\begin{array}{r}\text { I. Blutprobe } \\
\text { II. Blutprobe } \\
\text { (nach 15') }\end{array}$ & $\begin{array}{l}14,52 \\
13,94\end{array}$ & $-4,0$ & $\begin{array}{l}6,30 \\
5,86\end{array}$ & $-7,0$ & $\begin{array}{r}316 \\
272\end{array}$ & $-13,9$ & $\begin{array}{l}50,1 \\
46,4\end{array}$ & $-7,4$ & $\begin{array}{l}14,52 \\
13,94\end{array}$ & $-4,0$ \\
\hline 7 & $\begin{array}{c}1,98 \\
5\end{array}$ & $\begin{array}{r}\text { I. Blutprobe } \\
\text { II. Blutprobe } \\
\left.\text { (nach } 15^{\prime}\right)\end{array}$ & $\begin{array}{l}11,39 \\
10,21\end{array}$ & $-9,5$ & $\begin{array}{l}5,53 \\
5,49\end{array}$ & $-0,7$ & $\begin{array}{l}260 \\
247\end{array}$ & $-5,0$ & $\begin{array}{l}47,0 \\
45,0\end{array}$ & $-4,2$ & $\begin{array}{l}11,42 \\
10,41\end{array}$ & $-8,8$ \\
\hline & $\begin{array}{l}\text { urch- } \\
\text { hnitt }\end{array}$ & $\begin{array}{r}\text { I. Blutprobe } \\
\text { II. Blutprobe } \\
\left.\text { (nach } 15^{\prime}\right)\end{array}$ & $\begin{array}{l}14,25 \\
13,57\end{array}$ & $|-4,8|$ & $\begin{array}{l}5,90 \\
5,60\end{array}$ & $-4,8$ & $\begin{array}{l}261 \\
247\end{array}$ & $|-4,9|$ & $\begin{array}{l}44,1 \\
44,2\end{array}$ & $|+0,2|$ & $\left|\begin{array}{l}14,25 \\
13,60\end{array}\right|$ & $-4,7$ \\
\hline
\end{tabular}


eingebüsst hat, notwendigerweise ihr Bluteiweiss an das Blut abgeben. Da das so abzugebende Eiweiss anf dem Wege über die V. hepatica in das allgemeine zirkulierende Blut hineinströmt, habe ich folgendes Experiment in der Absicht angestellt, nämlich nach Entnahmen kleinerer oder grösserer Blutınengen Veränderungen des Eiweissgehaltes und des k.o.D. in dreierlei Bluten, also in Bluten der $V$. hepatica, V. portae und $A$. carotis zu bestimmen und sie vergleichend einer Betrachtung zu unterziehen.

I. Um mir zuerst ein Bild über das Verhalten der Leber gegenüber dem Bluteiweiss und dem k. o. D. nach Entnahme kleinerer Blutmengen zu gewinnen, habe ich an $7 \mathrm{Ver}$ suchen aus einem jeden Blutgefässe je $1,7 \mathrm{ccm}$, also insgesamt $5,1 \mathrm{ccm}$ Blut entnommen und 15 Minuten später abermals entsprechende Blut-

2.

Pfortader-sowie Carotisblutes durch geringe Blutentnahme.

\begin{tabular}{|c|c|c|c|c|c|c|c|c|c|c|c|c|c|}
\hline \multicolumn{6}{|c|}{ V. portae } & \multicolumn{8}{|c|}{ A. carotis } \\
\hline \multicolumn{2}{|c|}{$\begin{array}{l}\text { Serum- } \\
\text { eiweiss }\end{array}$} & \multicolumn{2}{|c|}{ K. o. D. } & \multicolumn{2}{|c|}{$\begin{array}{c}\text { Druck pro } \\
\%\end{array}$} & \multicolumn{2}{|c|}{$\begin{array}{l}\text { Hämo- } \\
\text { globin }\end{array}$} & \multicolumn{2}{|c|}{$\begin{array}{l}\text { Serum- } \\
\text { eiweiss }\end{array}$} & \multicolumn{2}{|c|}{ K. o. D. } & \multicolumn{2}{|c|}{$\begin{array}{c}\text { Druck pro } \\
\% \neq\end{array}$} \\
\hline$\%$ & $\left|\begin{array}{l}\text { Diffi. } \\
\text { in \% }\end{array}\right|$ & $\left(\begin{array}{l}\mathrm{mm} \\
\mathrm{H}_{2} \mathrm{O}\end{array}\right)$ & $\begin{array}{l}\text { Diff: } \\
\text { in } \%\end{array}$ & $\left(\begin{array}{c}\mathrm{mm} \\
\mathrm{H}_{2} \mathrm{O}\end{array}\right)$ & $\begin{array}{l}N_{1} \mathrm{ff} \\
\text { in } \%\end{array}$ & $(\mathrm{~g} / \mathrm{dl})$ & $\begin{array}{l}\text { Diff. } \\
\text { in } \%\end{array}$ & $(\%)$ & $\begin{array}{l}\text { Diff: } \\
\text { in } \%\end{array}$ & $\left(\begin{array}{l}\mathrm{nim} \\
\mathrm{H}_{2} \mathrm{O}\end{array}\right)$ & $\left|\begin{array}{c}\text { viti. } \\
\text { in } \%\end{array}\right|$ & $\overline{\left(\begin{array}{l}\mathrm{mm} \\
\mathrm{H}_{2} \mathrm{O}\end{array}\right)}$ & $\mid \begin{array}{l}\text { Diff: } \\
\text { in } \%\end{array}$ \\
\hline 5,53 & & 244 & & 44,1 & & $13,94 \mid$ & & 5,53 & & 242 & & 43,8 & \\
\hline 5,38 & $|-2,7|$ & 230 & $-5,7$ & 32,7 & $-3,2$ & 13,64 & $-2,1$ & 5,29 & $-4,3$ & 231 & $-4,5$ & 43,7 & $-0,2$ \\
\hline 5,94 & & 261 & & 43,9 & & 14,24 & & 5,92 & & 252 & & 42,6 & \\
\hline 5,36 & $\mid-9,8$ & 231 & $|-11,5|$ & 43,1 & $-1,8$ & 13,94 & $-2,1$ & 5,26 & $-10,6$ & 204 & $-19,0$ & 38,6 & $-9,4$ \\
\hline 5,97 & & 263 & & 44,0 & & 15,58 & & 5,86 & & 253 & & 43,2 & \\
\hline 5,79 & $-3,0$ & 245 & $-6,8$ & 42,3 & $-3,9$ & 15,08 & $-3,2$ & 5,77 & $-1,5$ & 243 & $-3,9$ & 42.1 & $-2, \tilde{5}$ \\
\hline 5,99 & & 248 & & 41,4 & & $|15,27|$ & & 5,97 & & 243 & & 40,7 & \\
\hline 5,47 & $|-8,7|$ & 224 & $-9,7$ & 40,9 & $-1,2$ & 14,24 & $-6,7$ & 5,49 & $-8,0$ & 218 & $-10,3$ & 39,7 & $-2,4$ \\
\hline $\begin{array}{l}6,47 \\
6,19\end{array}$ & $-4,3 \mid$ & $\begin{array}{l}295 \\
283\end{array}$ & $-4,1$ & $\begin{array}{l}45,6 \\
45,7\end{array}$ & $+0,2$ & $\begin{array}{l}14.80 \\
13,94\end{array}$ & $-5,8$ & $\begin{array}{l}6,47 \\
6,05\end{array}$ & $-6,5$ & $\begin{array}{l}294 \\
285\end{array}$ & $|-3,1|$ & $\begin{array}{l}45,4 \\
47,1\end{array}$ & $-3,7$ \\
\hline 6,42 & & 334 & & 52,0 & & 14,52 & & 6,42 & & 331 & & 51,5 & \\
\hline 6,08 & $-5,3$ & 299 & $-10,5$ & 49,2 & $-5,4$ & 13,94 & $-4,0$ & 5,97 & $-7,0$ & 297 & $-10,3$ & 49,7 & $-3,5$ \\
\hline 5,79 & & 261 & & 47,3 & & 11,39 & & 5,55 & & 261 & & 47,0 & \\
\hline 5,49 & $|-5,2|$ & 247 & $-5,4$ & 45,0 & $-4,9$ & $|10,44|$ & $-8,3$ & 5,43 & $-2,2$ & 254 & $-2,7$ & 46,8 & $-0,4$ \\
\hline 6,01 & & 272 & & 45,5 & & $|14,25|$ & & $5,96 \mid$ & & 268 & & 44,9 & \\
\hline 5,68 & $|-5,6|$ & 251 & $-7,7$ & 44,1 & $-2,9$ & 13,60 & $-4,6$ & 5,61 & $-5,7$ & 247 & $-7,7$ & 43,9 & $-2,1$ \\
\hline
\end{tabular}


entnahmen vorgenommen. Diese Resultate sind in Tab. 2 zusammengestellt. Es seien hier prozentuelle Ab-und Zunahmen der Daten der zweiten Blutproben gegenüber denselben der ersten Blutproben im Durchschnittswert angegeben.

Der Hämoglobingehalt nahm ab im Lebervenenblut um 4,8\%, im Pfortaderblut um 4,7\%, im Carotisblut um 4,6\%. Der Eiweissgehalt war vermindert im Lebervenenblut um $4,8 \%$, im Pfortaderblut um 5,6\% und im Carotisblut um 5,7\%. K. o. D. nahm ab im Lebervenenblut um $4,9 \%$, im Pfortaderblut um $7,7 \%$ und im Carotisblut um $7,7 \%$. Druck pro $\%$ wurde im Lebervenenblut um $0,2 \%$ vermehrt, im Pfortaderblut um 2,9\% und im Carotisblut um 2,1\% vermindert gefunden.

Dass bei Verlusten kleiner Blutmengen die Abnahme des Hämoglobins in annähernd gleichem Masse wie die des Eiweisses erfolgt, ist bereits von $\mathrm{It}^{32)}$ an hiesiger Klinik erwiese worden, und aus meinem Versuchsergebnisse hat es sich herausgestellt, dass bei Kaninchen hingegen selbst beim Blutverlust geringen Grades eine gewisse $\mathrm{Hy}$ drämie auftritt.

Im vorliegenden Versuch ist bemerkenswert die Feststellung, dass prozentische Abnahmen des Eiweissgehaltes und des k.o.D. sowie Drucks pro \% im Lebervenenblut kleiner als in anderen zwei Blutarten sind und dass der Druck pro \% meistens erhöht ist. Es ist dies dahin zu erklären, dass die Leber auch auf derartigen geringfügigen Blutverlust reagiert, nicht allein ihr Reserveeiweiss an das Blut abgibt, sondern weiterhin auch osmoaktive kleinmolekuläre Eiweissteilchen zu mobilisieren vermag.

II. Um mich darüber zu orientieren, inwieweit in der Leber Veränderungen des Bluteiweisses sowie des k.o.D., durch Entziehung grösserer Blutmengen eintreten, habe ich an 9 Kaninchen Aderlassversuch durchgeführt. Die Resultate sind in Tab. 3 zusammenfassend wiedergegeben.

Dem Vorschlag von $I_{t}{ }^{32}$ ) an hiesiger Klinik, der als eine Aderlassmenge

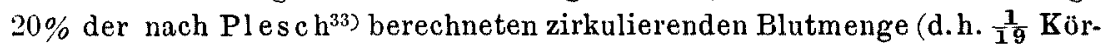
perge wicht), also $10 \mathrm{ccm}$ pro $\mathrm{kg}$ Körgerge wicht für geeignet hält, Folge leisstend, wurde sogleich, nachdem man aus drei Blutgefässen je 1,7ccm Blutproben entnommen hatte, an der A. carotis einen Aderlass von $10 \mathrm{~cm}$ pro kg Körpergewicht vorgenommen und 15 Minuten später abermals aus drei Blutgefässen je $1,7 \mathrm{ccm}$ Blutproben entzogen und daran Bestimmungen angestellt.

32) It o, Tohoku Journ. Exp. Med., 1929, 14, 236.

33) Plesch, Ztschr.f. exp. Path. u. Therap., 1909, 6, 380. 
Was prozentische Abnahmen der Daten der zweiten Blutproben gegenüber denselben der ersten Blutproben anbelangt, zeigt der Hämoglobingehalt in drei Blutarten gleichermassen reduzierte Werte von $13,5(18,8-7,5) \%$. Die Abnahme des Eiweissgehaltes beträgt im Lebervenenblut $3,3(-15,2-+7,1) \%$, im Pfortaderblut 9,7 $(-14,7-$ $+0,3) \%$ und im Carotisblut $11,1(-17,2--2,0) \%$. Die Abnahme des k.o.D. liegt im Lebervenenblut bei $4,8(-21,2-+19,6) \%$, im Pfortaderblut bei 18,4 $(-27,1--3,5) \%$ und endlich im Carotisblut bei $18,9(-27,1--9,6) \%$. Die Abnahme des Drucks pro \% beträgt im Lebervenenblut $1,8(-11,0-+11,8) \%$, im Pfortaderblut 9,8 $(-15,3--0,7) \%$, im Carotisblut 8,8 $(-13,1- \pm 0) \%$.

Githens, ${ }^{34)}$ Morawitz, ${ }^{35)}$ Inagaki, ${ }^{36)}$ Gottschalk und Nonnenbruch, ${ }^{37}$ Ozawa, ${ }^{17}$ Fischberg, ${ }^{38}$ Motai, ${ }^{39}$ Herzfeld und Klinger ${ }^{40}$ Cuvelier und Potoir, ${ }^{41)}$ Takeshita ${ }^{42}$ ) u.a. haben die nach Aderlässen auftretenden Veränderungen des Plasmaeiweisses verfolgt und gefunden, dass im Anfangsstadium das Albumin schnell, im Spätstadium das Globulin wiederhergestellt ist. Mithin steigt der Al/Gl Quotient, so behaupten genannte Forscher, im Anfangsstadium nach erfolgten Aderlasse an und dann allmählich ab.

In vorliegenden Versuchsergebnissen fällt nun auf, dass zwar zwischen Veränderungen des Pfortader- und Carotisblutes kein grosser Unterschied besteht, dass aber prozentische Abnahmen des Eiweissgehaltes und des k.o.D. sowie Drucks pro \% im Lebervenenblut nicht nur auffallend kleiner als dieselben in anderen zwei Blutarten sind, sondern die Daten des erstgenannten Blutes mitunter auch über die Werte vor Aderlässen hinaussteigen, eine Erscheinung welche in anderen zwei Blutarten gar nicht zum Vorschein kam. Es ist dies also höchstwahrscheinlich nichts anders als ein Anzeichen dafür, dass die Leber, ein Eiweissstapelplatz, unmittelbar nach Aderlässen nicht allein ihr Reserveeiweiss mobilisiert, sondern auch osmoaktive kleinmolekuläre Eiweissteilchen an das Blut abgibt, damit der k.o.D. des Blutes unter optimalen Verhältnissen erhalten werden könnte.

III. In oben angeführten Versuclien wurden nur Veränderungen, die nach einmaliger Entnahme der kleineren oder grösseren Blut-

34) Githens, Beiträge z. chem. Physiol. u. Pathol., 1903, 5, 515.

35) Mora wit 2 , Ibid., 1906, $7,153$.

36) In ag a ki, Ztschr. f. Biol., 1907, 49, 75.

37) Gottschalk u. Nonnenbruch, Arch. f. exp. Path. u. Pharm., 1923, 96, 115.

38) Fis chberg, Biochem. Ztschr., 1928, 195, 20.

39) Motai, Aichi Ikadaigaku Zasshi, 1930, 37, 1158.

40) Herzfeld u. Klinger, Biochem. Ztsehr., 1932, 254, 414.

41) Cuvelier u. Potoir, C.r. Soc. Biol., 1932, 111, 16.

42) Takeshita, Kyoto Furitsu Ikadaigaku Zasshi, 1934, 12, 534. 
Tabelle

Veränderungen des Eiweissgehalts und k. o. D. des Lebervenen-, Pfortader-

\begin{tabular}{|c|c|c|c|c|c|c|c|c|c|c|c|c|}
\hline \multirow{3}{*}{ 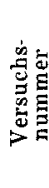 } & \multirow{3}{*}{ 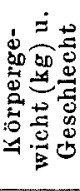 } & \multirow{3}{*}{$\begin{array}{l}\text { Zeit d. } \\
\text { Blutentnahme }\end{array}$} & \multicolumn{8}{|c|}{ V. hepatica } & & \\
\hline & & & \multicolumn{2}{|c|}{$\begin{array}{l}\text { Hämo- } \\
\text { globin }\end{array}$} & \multicolumn{2}{|c|}{$\begin{array}{l}\text { Serum- } \\
\text { eiweiss }\end{array}$} & \multicolumn{2}{|c|}{ K. o. D. } & \multicolumn{2}{|c|}{$\begin{array}{c}\text { Druck pro } \\
\%\end{array}$} & \multicolumn{2}{|c|}{$\begin{array}{l}\text { Hämo- } \\
\text { globin }\end{array}$} \\
\hline & & & $(g / \mathrm{dl})$ & ) $\begin{array}{l}\text { vitr. } \\
\text { in \% }\end{array}$ & $(\%)$ & $\begin{array}{c}\text { Diff. } \\
\text { in \% }\end{array}$ & $\left(\begin{array}{l}\mathrm{mm} \\
\mathrm{H}_{2} \mathrm{O}\end{array}\right)$ & $\begin{array}{c}\text { Diff. } \\
\text { in } \%\end{array}$ & $\left(\begin{array}{c}\mathbf{m m} \\
\mathrm{H}_{2} \mathbf{0}\end{array}\right)$ & $\begin{array}{c}\text { Diff. } \\
\text { in } \%\end{array}$ & $(\mathrm{~g} / \mathrm{dl})$ & $\begin{array}{l}\text { Dift. } \\
\text { in \% }\end{array}$ \\
\hline 1 & $\begin{array}{c}2,20 \\
\delta\end{array}$ & ss & $\mid$\begin{tabular}{|l|}
14,80 \\
12,80
\end{tabular} & $-13,5$ & $\begin{array}{l}6,36 \\
6,81\end{array}$ & $+7,1$ & $\begin{array}{l}285 \\
341\end{array}$ & $+19,6$ & $\begin{array}{l}4,8 \\
0,1\end{array}$ & $+11,8$ & \begin{tabular}{|l|}
14,80 \\
12,80
\end{tabular} & \\
\hline 2 & $\begin{array}{c}1,95 \\
\hat{0}\end{array}$ & & $\left|\begin{array}{l}13,64 \\
11,66\end{array}\right|$ & $\mid-14,5$ & $\mid \begin{array}{l}5,68 \\
5,68\end{array}$ & $\mid \pm 0$ & 2 & $|+1,2|$ & $\begin{array}{l}1 \\
6\end{array}$ & $\mid+1,1$ & \begin{tabular}{|l|}
13,64 \\
11,66
\end{tabular} \mid & 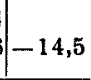 \\
\hline 3 & $\begin{array}{c}2,16 \\
q\end{array}$ & & 52 & & $\left|\begin{array}{l}5,68 \\
5,90\end{array}\right|$ & $+3,9$ & & $+6,4$ & & $+2,4$ & $\begin{array}{l}14,52 \\
12,52\end{array}$ & 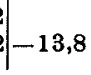 \\
\hline 4 & $\begin{array}{c}2,90 \\
\hat{\delta}\end{array}$ & $s s$ & $\begin{array}{l}15,08 \\
12,52\end{array}$ & 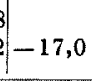 & $\left|\begin{array}{l}5,45 \\
5,27\end{array}\right|$ & $-3,3$ & 2 & $-7,0$ & 9 & 3,8 & $\begin{array}{l}15,08 \\
12,52 \\
\end{array}$ & $-17,0$ \\
\hline 5 & $\begin{array}{l}1,80 \\
\stackrel{p}{+}\end{array}$ & & \begin{tabular}{|l|}
15,08 \\
12,24
\end{tabular} & & $\left|\begin{array}{l}5,38 \\
5,25\end{array}\right|$ & $\mid-2,4$ & 228 & $-0,9$ & & $+1-3,3$ & \begin{tabular}{|l|}
15,08 \\
12,24
\end{tabular} & $-18,8$ \\
\hline 6 & $\begin{array}{c}2,15 \\
q\end{array}$ & $\mathrm{Nac}$ & \begin{tabular}{|l|}
15,08 \\
13,94
\end{tabular} & 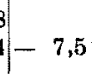 & $\begin{array}{l}5,47 \\
5,09\end{array}$ & $-6,9$ & & $-11,3$ & & $-4,6$ & $\begin{array}{l}15,08 \\
13,94\end{array}$ & $-7,5$ \\
\hline 7 & $\begin{array}{c}2,00 \\
3\end{array}$ & ss & \begin{tabular}{|l|}
16,20 \\
13,64
\end{tabular} & & $\mid \begin{array}{l}6,10 \\
6,03\end{array}$ & $\mid-1,1$ & $\begin{array}{l}3 \\
2\end{array}$ & -12.0 & & $-11,0$ & $\begin{array}{l}16,20 \\
13,64 \\
\end{array}$ & $-15,8$ \\
\hline 8 & $\begin{array}{c}2,30 \\
\hat{b}\end{array}$ & & ,08 & 8 & \begin{tabular}{|l|}
6,14 \\
5,40
\end{tabular} & - & & $-19,6$ & $\begin{array}{l}0 \\
2\end{array}$ & 8,6 & $\begin{array}{l}13,08 \\
11,66\end{array}$ & $\mid-10$ \\
\hline 9 & $\begin{array}{c}2,27 \\
8\end{array}$ & $\mathrm{~N}$ & 28 & $-9,9$ & $\begin{array}{l}5,25 \\
4,45\end{array}$ & $-15,2$ & & $-21,2$ & $\begin{array}{l}41,3 \\
38,4\end{array}$ & $-7,0$ & $\begin{array}{l}14,52 \\
13,08\end{array}$ & -9 \\
\hline & & & $\begin{array}{l}14,67 \\
12,67\end{array}$ & $-13,5$ & $\left|\begin{array}{l}5,72 \\
5,54\end{array}\right|$ & $-3,3$ & 244 & $-4,8$ & $\begin{array}{l}44,5 \\
43,6\end{array}$ & $-1,8$ & 12,67 & $-13,5$ \\
\hline
\end{tabular}

mengen auftraten, beobachtet; um mir aber weiterhin Klarheit darüber zu gewinnen, wie sich die Leber dann, wenn der Organismus durch wiederholte Entnahmen der mittelmässigen Blutmengen allmählich an Bluteiweiss verloren hat, verhalten würde, habe ich folgende Ver'suche angestellt.

Es wurden jedem Versuchstier aus der Ohrvene jeden Tag oder jeden zweiten Tag je 5-15 ccm, insgesamt 112-135 ccm Blut entnommen und demjenigen Kaninchen, dessen Erythrozytenzahl unter die Hälfte des Anfangswertes herabfiel, wurden aus dreierlei Blutgefässen, d.h. V.hepatica, V. portae und A.carotis, Blutproben von $1,7 \mathrm{ccm}$ entnommen, und an diesen die Bestimmungen ausgeführt. Da in vorliegenden Versuchen zweimalige Operationen zur Blutentnahme aus der Lebervene und Pfortader unausführbar waren, so war es unmög- 
3.

sowie Carotisblutes durch Aderlass $(10 \mathrm{ccm}$ pro kg Körpergewicht.

\begin{tabular}{|c|c|c|c|c|c|c|c|c|c|c|c|c|c|}
\hline \multicolumn{6}{|c|}{ V. portae } & \multicolumn{8}{|c|}{ A. carotis } \\
\hline \multicolumn{2}{|c|}{$\begin{array}{l}\text { Serum- } \\
\text { eiweiss }\end{array}$} & \multicolumn{2}{|c|}{ K. o. D. } & \multicolumn{2}{|c|}{$\begin{array}{c}\text { Druck pro } \\
\%\end{array}$} & \multicolumn{2}{|c|}{$\begin{array}{l}\text { Hämo- } \\
\text { globin }\end{array}$} & \multicolumn{2}{|c|}{$\begin{array}{l}\text { Serum- } \\
\text { eiweiss }\end{array}$} & \multicolumn{2}{|c|}{ S. o. D. } & \multicolumn{2}{|c|}{$\begin{array}{c}\text { Druck pro } \\
\% \%\end{array}$} \\
\hline$(\%)$ & $\begin{array}{l}\text { Diff. } \\
\text { in } \%\end{array}$ & $\left(\begin{array}{l}\mathrm{mm}_{\mathrm{H}_{2} \mathrm{O}}\end{array}\right)$ & $\begin{array}{l}\text { Diff. } \\
\text { in } \%\end{array}$ & $\left(\begin{array}{l}\mathrm{mm} \\
\mathrm{H}_{2} \mathrm{O}\end{array}\right)$ & $\begin{array}{l}\text { Diff. } \\
\text { in } \%\end{array}$ & $(g / d l)$ & $\left|\begin{array}{c}\text { Diff } \\
\text { in } \%\end{array}\right|$ & $(\%)$ & $\left|\begin{array}{c}D_{\text {iff }} \\
\text { in } \%\end{array}\right|$ & $\left(\begin{array}{l}\mathrm{min} \\
\mathrm{H}_{2} \mathrm{O}\end{array}\right)$ & $\begin{array}{c}\text { Diff: } \\
\text { in } \%\end{array}$ & $\left.\begin{array}{l}\mathrm{mm} \\
\mathrm{H}_{\mathrm{g}} \mathrm{O}\end{array}\right)$ & $\begin{array}{l}\text { Diff. } \\
\text { in } \% \\
\end{array}$ \\
\hline $\begin{array}{l}6,47 \\
6,08\end{array}$ & $-6,0$ & $\begin{array}{l}303 \\
253\end{array}$ & $-16,5$ & $\begin{array}{l}46,8 \\
41,6\end{array}$ & $-11,1$ & \begin{tabular}{|}
14,80 \\
12,80
\end{tabular} \mid & $-13,5$ & $\begin{array}{l}6,38 \\
6,25\end{array}$ & $-2,0$ & $\begin{array}{l}291 \\
263\end{array}$ & $-9,6$ & $\begin{array}{l}45,6 \\
42,1\end{array}$ & $-7,7$ \\
\hline $\begin{array}{l}5,97 \\
5,23\end{array}$ & $-12,4$ & $\begin{array}{l}289 \\
227\end{array}$ & $|-21,4|$ & $\begin{array}{l}48,4 \\
43,4\end{array}$ & $-10,3 \mid$ & $\left|\begin{array}{l}13,64 \\
11,66\end{array}\right|$ & $-14,5$ & $\begin{array}{l}6,01 \\
5,27\end{array}$ & $|-12,3|$ & $\begin{array}{l}294 \\
224\end{array}$ & $-23,8$ & $\begin{array}{l}48,9 \\
42,5\end{array}$ & $-13,1$ \\
\hline $\begin{array}{l}5,70 \\
5,72\end{array}$ & $+0,3$ & $\begin{array}{l}283 \\
273\end{array}$ & $|-3,5|$ & $\begin{array}{l}49,6 \\
47,7\end{array}$ & $|-3,8|$ & $\left|\begin{array}{l}14,52 \\
12,52\end{array}\right|$ & $-13,9$ & $\begin{array}{l}6,01 \\
5.29\end{array}$ & $-12,0$ & $\begin{array}{l}302 \\
266\end{array}$ & $\mid-11,9$ & $\begin{array}{l}50,2 \\
50,2\end{array}$ & \pm 0 \\
\hline $\begin{array}{r}5,83 \\
5,16 \\
\end{array}$ & $-11, \tilde{0}$ & $\begin{array}{l}239 \\
188\end{array}$ & $-21,3$ & $\begin{array}{l}41,0 \\
36,4\end{array}$ & $-11,2$ & \begin{tabular}{|l|}
15,08 \\
12,52
\end{tabular} & $-17,0$ & $\begin{array}{l}5,81 \\
4,81\end{array}$ & $-17,2$ & $\begin{array}{l}236 \\
172\end{array}$ & $|-27,1|$ & $\begin{array}{l}40,6 \\
35,7\end{array}$ & $-12,1$ \\
\hline $\begin{array}{l}5,58 \\
5,38\end{array}$ & $-3,6$ & $\begin{array}{l}235 \\
225\end{array}$ & $-4,2$ & $\begin{array}{l}42,1 \\
41,8\end{array}$ & $-0,7$ & $\left|\begin{array}{l|}15,08 \\
12,24\end{array}\right|$ & $-18,8$ & $\begin{array}{l}5,68 \\
4,92\end{array}$ & $-13,4$ & $\begin{array}{l}244 \\
211\end{array}$ & -13.5 & $\begin{array}{l}42,9 \\
42,9\end{array}$ & \pm 0 \\
\hline $\begin{array}{l}5,64 \\
4,88 \\
\end{array}$ & $-13,5$ & $\begin{array}{l}269 \\
197\end{array}$ & $-26,8$ & $\begin{array}{l}47,7 \\
40,4 \\
\end{array}$ & $-15,3$ & \begin{tabular}{|l|}
15,08 \\
13,94
\end{tabular} & $-7,5$ & $\begin{array}{l}5,58 \\
\mathbf{4}, 81\end{array}$ & $|-13,8|$ & $\begin{array}{l}266 \\
200\end{array}$ & $-24,8$ & $\begin{array}{l}47,7 \\
41,6\end{array}$ & $-12,8$ \\
\hline $\begin{array}{l}6,59 \\
5,62\end{array}$ & $-14,7$ & $\begin{array}{l}330 \\
246\end{array}$ & $-25,4$ & $\begin{array}{l}50,1 \\
43,8\end{array}$ & $-12,6 \mid$ & $\left|\begin{array}{l}16,20 \\
13,64\end{array}\right|$ & $-15,8$ & $\begin{array}{l}6,21 \\
6,08\end{array}$ & $|-2,1|$ & $\begin{array}{l}310 \\
268\end{array}$ & $|-13,5|$ & $\begin{array}{l}49,9 \\
44,1\end{array}$ & $-11,6$ \\
\hline $\begin{array}{l}6,21 \\
5,47\end{array}$ & $-11,9$ & $\begin{array}{l}276 \\
221\end{array}$ & $-19,9$ & $\begin{array}{l}44,0 \\
40,4\end{array}$ & $-8,2$ & \begin{tabular}{|}
13,08 \\
11,66 \\
\end{tabular} & $-10,8$ & $\begin{array}{l}6,16 \\
5,40\end{array}$ & $-12,3$ & $\begin{array}{l}273 \\
217\end{array}$ & $-20,5$ & $\begin{array}{l}44,3 \\
40,2\end{array}$ & $-9,2$ \\
\hline $\begin{array}{l}5,38 \\
4,62\end{array}$ & $-14,1$ & $\begin{array}{l}236 \\
172\end{array}$ & $-27,1$ & $\begin{array}{l}43,9 \\
37,2\end{array}$ & $|-15,3|$ & \begin{tabular}{|l|}
14,52 \\
13,08
\end{tabular} & $-9,9$ & $\begin{array}{l}5,36 \\
4,58\end{array}$ & $-14,5$ & $\begin{array}{l}233 \\
174\end{array}$ & $|-25,3|$ & $\begin{array}{l}43,5 \\
38,0\end{array}$ & $-12,6$ \\
\hline $\begin{array}{l}5,93 \\
5,35\end{array}$ & $-9,7$ & $\begin{array}{l}273 \\
222\end{array}$ & $-18,4$ & $\begin{array}{l}45,9 \\
41,4\end{array}$ & $-9,8 \mid$ & $\begin{array}{l}14,67 \\
12,67\end{array}$ & $-13,5$ & $\begin{array}{l}5,91 \\
5,27\end{array}$ & $-11,1$ & $\begin{array}{l}272 \\
222\end{array}$ & $-18,9$ & $\begin{array}{l}45,9 \\
41,9\end{array}$ & $-8,8$ \\
\hline
\end{tabular}

lich, an ein und demselben Versuchstier die Daten vor und nach dem Eintritt der Anämie gegeneinander zu vergleichen.

An 6 anämischen Kaninchen erhobene Daten sind in Tab. 4 wiedergegeben. Der Hämoglobingehalt betrug in drei Blutarten gemeinschaftlich $7,58(8,52-5,96) \mathrm{g} / \mathrm{dl}$. Der Eiweissgehalt betrug im Lebervenenblut 5,55 (7,09-4,25) \%, im Pfortaderblut 5,69 (7,05-4,20)\%, im Carotisblut 5,68(7,05-4,27)\%. K.o.D. wurde im Lebervenenblut zu $240(319-180) \mathrm{mm} \mathrm{H}_{2} \mathrm{O}$, im Pfortaderblut zu $240(305-175) \mathrm{mm} \mathrm{H}_{2} \mathrm{O}$, im Carotisblut zu $239(309-177) \mathrm{mm} \mathrm{H}_{2} \mathrm{O}$ ermittelt. Druck pro \% betrug im Lebervenenblut $42,9(45,2-39,1) \mathrm{mm} \mathrm{H}_{2} \mathrm{O}$, im Pfortaderblut $42,1(44,7-38,9) \mathrm{mm} \mathrm{H}_{2} \mathrm{O}$ und im Carotisblut $42,2(44,6-38,9) \mathrm{mm} \mathrm{H}_{2} \mathrm{O}$. 


\begin{tabular}{|c|c|c|c|c|c|c|c|c|c|c|}
\hline \multirow{19}{*}{ 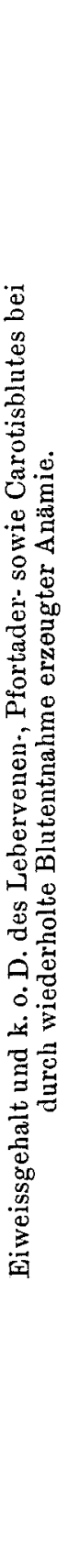 } & \multirow{2}{*}{ 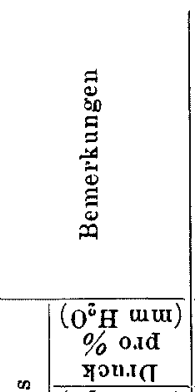 } & \multicolumn{7}{|c|}{ 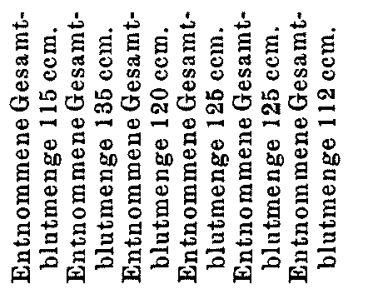 } & \multirow[b]{2}{*}{ 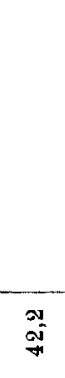 } & \multirow[b]{2}{*}{$\begin{array}{l}\infty \\
\sigma^{-}\end{array}$} \\
\hline & & $\underset{\infty}{\infty}$ & $m_{n}^{\infty}$ & $\stackrel{0}{\#}$ & $\stackrel{\infty}{q}$ & $\stackrel{0}{\infty}$ & $\stackrel{\#}{=}$ & $\stackrel{\pi}{10}$ & & \\
\hline & $\begin{array}{c}\left(0^{\bar{\tau}} \mathrm{H} \text { ulur }\right) \\
\mathbf{\sigma}^{\circ} \cdot 0^{\circ} \cdot \mathrm{Y}\end{array}$ & $\begin{array}{l}\text { a } \\
\text { 吕 } \\
\text { ON }\end{array}$ & $\overrightarrow{\mathrm{O}}$ & $\stackrel{0}{a}$ & $\begin{array}{l}\infty \\
\mathscr{Q} \\
0\end{array}$ & g & $\approx$ & $\vec{E}$ & 哥 & $\begin{array}{l}\infty \\
=\end{array}$ \\
\hline & 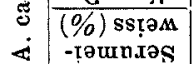 & 禁 & $\frac{0}{10}$ & $\frac{9}{10}$ & $\overline{0}$ & $\stackrel{8}{2}$ & $\underset{\mathrm{a}}{\mathrm{a}}$ & $\underset{8}{\stackrel{8}{8}}$ & $\begin{array}{l}\infty \\
0 \\
0 \\
0\end{array}$ & $\frac{1}{10}$ \\
\hline & $\begin{array}{l}\text { (Ip/g) utq } \\
\text {-o[souph }\end{array}$ & $\stackrel{5}{\mathscr{S}}$ & 虹 & 拿 & $\begin{array}{l}\mathscr{8} \\
5 \\
10\end{array}$ & $\begin{array}{l}\mathbb{N} \\
\infty \\
\infty\end{array}$ & $\stackrel{N}{=}$ & 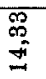 & $\begin{array}{l}\infty \\
10 \\
10 \\
10\end{array}$ & $\bar{E}$ \\
\hline & $\begin{array}{c}\left(0_{\%}^{6} \mathrm{H} \text { usua }\right) \\
\% \text { oxd } \\
\text { yon.x }\end{array}$ & $\frac{\sigma}{\infty}$ & $\begin{array}{l}\infty \\
\infty \\
\infty\end{array}$ & $\stackrel{\infty}{=}$ & $\frac{5}{\pi}$ & $\stackrel{\infty}{\infty}$ & $\Rightarrow$ & 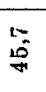 & $\overrightarrow{\mathrm{a}}$ & $\stackrel{\infty}{\infty}$ \\
\hline & 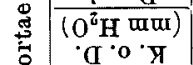 & $\begin{array}{l}N \\
\text { a } \\
\text { a }\end{array}$ & $\overrightarrow{\mathrm{O}}$ & $\frac{\pi}{a}$ & $\underset{\mathrm{N}}{\mathrm{N}}$ & $\stackrel{10}{8}$ & $\stackrel{20}{=}$ & L & $\stackrel{\circ}{a}$ & $\stackrel{0}{9}$ \\
\hline & 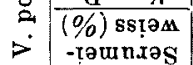 & 管 & $\begin{array}{l}\text { Do } \\
\frac{1}{10}\end{array}$ & $\frac{\omega}{20}$ & $\stackrel{0}{0}_{0}^{0}$ & $\underset{10}{0}$ & 啇 & $\begin{array}{c}9 \\
0 \\
0 \\
0\end{array}$ & $\begin{array}{l}8 \\
8 \\
15\end{array}$ & $\stackrel{0}{0}$ \\
\hline & $\begin{array}{l}\text { (Ip/a) u!̣q } \\
\text {-o[əัouย̣H }\end{array}$ & $\stackrel{9}{9}$ & $\underset{1}{0}$ & 点 & $\mathscr{\sigma}_{10}^{\circ}$ & i⿱ & $\stackrel{N}{=}$ & 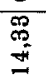 & $\stackrel{\infty}{\infty}$ & $=$ \\
\hline & $\begin{array}{c}\left(0^{\bar{\sigma}} \mathrm{H} \text { uw }\right) \\
\% \text { odd } \\
\text { yond } \\
\end{array}$ & $\vec{a}$ & $\stackrel{4}{\pi}$ & $\underset{\pi}{\pi}$ & is & $\begin{array}{l}0 \\
10\end{array}$ & $\stackrel{\infty}{\mathfrak{*}}$ & $\underset{j}{\infty}$ & $\stackrel{g}{\pi}$ & os \\
\hline & 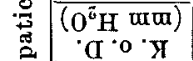 & 承 & $\stackrel{\varphi}{a}$ & $\stackrel{\circ}{a}$ & 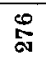 & $\frac{\sigma}{\infty}$ & $\stackrel{8}{\infty}$ & $\oint_{\infty}$ & $\stackrel{8}{\mathcal{H}}$ & $\Xi$ \\
\hline & 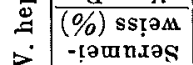 & $\begin{array}{l}0 \\
0 \\
0 \\
0\end{array}$ & $\stackrel{8}{\pi}$ & $\stackrel{\mathscr{g}}{+}$ & $\frac{9}{8}$ & $\stackrel{9}{0}$ & 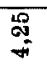 & $\begin{array}{l}\infty \\
\infty \\
10\end{array}$ & $\begin{array}{l}10 \\
6 \\
5\end{array}$ & 8 \\
\hline & $\begin{array}{l}\text { (ip/s) u!q } \\
\text {-o[sourer }\end{array}$ & $\stackrel{\mathscr{D}}{\circ}$ & $\frac{0}{2}$ & ס & $\stackrel{0}{10}$ & 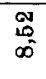 & $\stackrel{\infty}{2}$ & $\underset{m}{m}$ & $\begin{array}{l}\infty \\
0 \\
\infty \\
\infty\end{array}$ & $=$ \\
\hline & 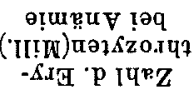 & बे & 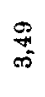 & $\frac{20}{n}$ & $=$ & $\stackrel{\bullet}{\bullet}$ & 是 & $\stackrel{9}{巳}$ & 宫 & 苟 \\
\hline & 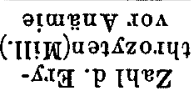 & $\begin{array}{l}\infty \\
\infty \\
\infty\end{array}$ & $\stackrel{\alpha}{=}$ & $\overrightarrow{0}$ & 象 & $\stackrel{0}{0}$ & $\stackrel{\infty}{\infty}_{0}^{\infty}$ & $\underset{\mathscr{Z}}{E}$ & 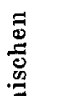 & 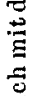 \\
\hline & 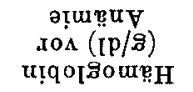 & $\begin{array}{l}\infty \\
\text { i⿱口口 } \\
\text { on } \\
-2\end{array}$ & à & $\begin{array}{l}8 \\
\stackrel{1}{0} \\
0\end{array}$ & $\stackrel{+}{\infty}$ & $\stackrel{\infty}{ \pm}$ & $\stackrel{\oplus}{ \pm}$ & 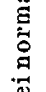 & $\underset{0}{3}$ & $\stackrel{9}{50}$ \\
\hline & 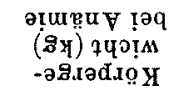 & $\cong$ & 5 & $\stackrel{\infty}{=}$ & $\approx$ & $\underset{\substack{\text { oิ } \\
\text { oิ }}}{ }$ & $\stackrel{\infty}{\infty}$ & 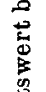 & 这恋 & 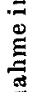 \\
\hline & 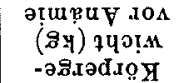 & $\stackrel{\mathscr{\infty}}{=}$ & के & $\underset{8}{0}$ & $\infty$ & कo & $\frac{a}{a}$ & $\frac{E}{E}$ & 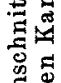 & 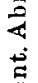 \\
\hline & 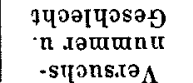 & њ & $\infty$ & to & + & 10 & $\infty$ & 宽 & 它 & 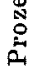 \\
\hline
\end{tabular}


Der bequemen Vergleichbarkeit halber sind prozentische Abnahmen, die sich aus dem Vergleich der hier gewonnenen Durchschnittswerte mit an normalen Kaninchen erhobenen Durchschnittswerten ergaben, an unterer Kolumne der Tab. 4 beigefügt. Die prozentische Abnahme des Hämoglobins betrug nämlich in drei Blutarten in eben gemeinschaftlicher Weise 47,1\%. Die prozentische Abnahme des Eiweissgehaltes betrug im Lebervenenblut 5,3\%, im Pfortaderblut 5,5\% und im Carotisblut 5,2\%. Dieselbe des k.o.D. belief sich im Lebervenenblut auf 7,7\%, im Pfortaderblut auf $13,0 \%$ und im Carotisblut auf $11,8 \%$. Dieselbe des Drucks pro \% betrug im Lebervenenblut 2,9\%, im Pfortaderblut 7,9\% und im Carotisblut 6,8\%.

Aus eben angeführten Daten gehen folgende Befunde hervor: Die prozentischen Abnahmen des k.o.D. und des Drucks pro \% gegenüber entsprechenden Grössen des normalen Kaninchens sind im Lebervenenblut am geringsten unter den drei Blutarten, und während der Druck pro \% des Lebervenenblutes bei normalen Kaninchen sich gegenüber demselben der anderen zwei Blutarten als der geringste erweis, zeigte er bei anämischen Kaninchen umgekehrt den maximalen Wert. Diese Tatsache dürfte mit voller Sicherheit dahingedeutet werden, dass die Leber, auf wiederholte Bluteiweissverluste reagierend, um die Wiederherstellung der optimalen Verhältnisse des k.o.D. des Blutes sehr bestrebt ist, indem sie osmoaktive kleinmolekuläre Eiweissteilchen produziert.

III. Veränderungen des Eiweissgehaltes und des k. o. D. des Lebervenen-, Pfortader- und Carotisblutes nach Ausführung. der Plasmaphäresis.

In jüngster Zeit hat Fukuhara ${ }^{43)}$ an hiesiger Klinik den Nachweis erbracht, dass, als er an Kaninchen aus zirkulierendem Blut, ohne etwa Anämie oder Hydrämie hervorgerufen zu haben, möglichst reichliche Mengen Bluteiweisses entzog (Plasmaphäresis), der Organismus gleich darauf über die $Z$ weckmässigkeitseinrichtung verfügte, d.h. mit der Wiederherstellung des Bluteiweisses sowie dessen k.o.D. begann, sodass ihre vollständige Wiederherstellung schon innerhalb von mehreren Tagen bewerkstelligt wurde. Er hat nachdrücklich hervorgehoben, dass beim Vorgang derartiger Wiederherstellung im

43) Fukuhara, Tohoku Journ. Exp. Med., 1937, 30, 465. 
besonderen die Leber als ein Eiweissdepotorgan am hervorragendsten beteiligt sein müsse.

Da man nach der von Fukuhara angewandten Methode der Plasmaphäresis, ohne dass man die Abnahme der Erythrozytenzahl herbeizuführen braucht, äusserst hochgradigen Bluteiweissverlust (ca. $30 \%$ ) erzielen kann, so tritt nach der Plasmaphäresis die Reaktion des Organismus auf die Erholung des Eiweisses und des k.o.D. hin in weitgehend stärkerem Masse als bei oben erwähnter Aderlassanämie hervor. Es drängte nun mir die Frage auf: Wie verhalten sich dann der Eiweissgehalt und der k.o.D. des Lebervenenblutes, wenn das Bluteiweiss nach Ausführung der Plasmaphäresis zuzunehmen anfängt? Um mich darüber zu vergewissern habe ich folgendes Experiment angestellt.

Es wurden jedem Versuchskaninchen aus dreierlei Blutgefässen: A. carotis, $\mathrm{V}$. portae und V. hepatica, auf ganz dieselbe Weise, wie weit oben geschildert, je $1,7 \mathrm{ccm}$ Blut entnommen. Im direkten Anschluss daran wurde ein Aderlass von 40-60 ccm an der A. carotis vorgenommen, und als der Aderlass sich zu vollenden eben im Begriff war, wurde unter streng aseptischen Kautelen das sog. ent-

Tabelle

Veränderungen des Eiweissgehalts und k. o. D. des Leber

\begin{tabular}{|c|c|c|c|c|c|c|c|c|c|c|c|c|c|c|}
\hline \multirow{3}{*}{ 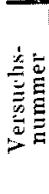 } & \multirow{3}{*}{ 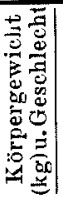 } & \multirow{3}{*}{$\begin{array}{l}\text { Zeit d. } \\
\text { Blutentuahme }\end{array}$} & \multicolumn{8}{|c|}{ V. hepatica } & & & & \\
\hline & & & \multicolumn{2}{|c|}{$\begin{array}{l}\text { Hämo- } \\
\text { globin }\end{array}$} & \multicolumn{2}{|c|}{$\begin{array}{l}\text { Serum- } \\
\text { eiweiss }\end{array}$} & \multicolumn{2}{|c|}{ K. o. D. } & \multicolumn{2}{|c|}{$\begin{array}{c}\text { Druck pro } \\
\%\end{array}$} & \multicolumn{2}{|c|}{$\begin{array}{l}\text { Hämo- } \\
\text { globin }\end{array}$} & \multicolumn{2}{|c|}{$\begin{array}{l}\text { Serum- } \\
\text { eiweiss }\end{array}$} \\
\hline & & & $(\mathrm{g} / \mathrm{dl})$ & $\begin{array}{l}\text { Diff. } \\
\text { in \% }\end{array}$ & $(\%)$ & $\begin{array}{l}\text { Diff. } \\
\text { in } \%\end{array}$ & $\left(\begin{array}{c}\mathrm{mm} \\
\mathrm{H}_{2} \mathrm{O}\end{array}\right)$ & $\begin{array}{l}\text { Diff. } \\
\text { in } \%\end{array}$ & $\left(\begin{array}{l}m m \\
H_{2} 0\end{array}\right)$ & $\begin{array}{l}\text { Diffi. } \\
\text { in \% }\end{array}$ & $(\mathrm{g} / \mathrm{dl})$ & $\begin{array}{l}\text { Ditf. } \\
\text { in \% }\end{array}$ & $(\%)$ & $\begin{array}{l}\text { Nitt. } \\
\text { in } \%\end{array}$ \\
\hline 1 & $\left|\begin{array}{c}2,17 \\
0\end{array}\right|$ & $\begin{array}{l}\text { Vor d. Plasma- } \\
\text { phäresis } \\
\text { Nach } 15 \text { Min. }\end{array}$ & $\begin{array}{l}14,52 \\
13,64\end{array}$ & $-6,1$ & $\left|\begin{array}{l}5,58 \\
4,14\end{array}\right|$ & $-25,8$ & $\begin{array}{l}244 \\
148\end{array}$ & $-39,3$ & $\begin{array}{l}43,7 \\
35,7\end{array}$ & $-18,3$ & $\left|\begin{array}{l}14,52 \\
13,64\end{array}\right|$ & $-6,1$ & \begin{tabular}{|l|}
5,68 \\
3,87
\end{tabular} & - \\
\hline 2 & $\begin{array}{c}1,82 \\
1\end{array} \mid$ & $\begin{array}{l}\text { Vord. I } \\
\text { phäres } \\
\text { Nach } 15\end{array}$ & $\begin{array}{l}14,24 \\
14,20\end{array} \mid$ & $-0,3$ & $\left|\begin{array}{l}4,73 \\
3,50\end{array}\right|$ & $-26,0$ & $\begin{array}{l}186 \\
131\end{array}$ & $-26,5$ & $\begin{array}{l}39,3 \\
37,4\end{array}$ & $-4,8$ & $\left|\begin{array}{l}14,24 \\
14,20\end{array}\right|$ & 0,3 & $\left|\begin{array}{l}4,94 \\
3,28\end{array}\right|$ & $-33,6$ \\
\hline 3 & $\mid \begin{array}{c}2,08 \\
\hat{\delta}\end{array}$ & $\begin{array}{l}\text { Vord. Plasina- } \\
\text { phäresis } \\
\text { Nach } 15 \text { Min. }\end{array}$ & \begin{tabular}{|l|}
14,80 \\
15,08
\end{tabular} \mid & $+1,9$ & $\left|\begin{array}{l}5,77 \\
4,45\end{array}\right|$ & $-22,9$ & $\begin{array}{l}238 \\
167\end{array}$ & $-29,8$ & $\begin{array}{l}41,2 \\
37,5\end{array}$ & $-9,0$ & $\left|\begin{array}{l}14,80 \\
15,08\end{array}\right|$ & $+1,9$ & $\begin{array}{l}5,93 \\
4,42\end{array}$ & $-25,5$ \\
\hline 4 & $\begin{array}{c}1,95 \\
8\end{array}$ & $\begin{array}{l}\text { Vord. Plasma- } \\
\text { phäresis } \\
\text { Nach } 15 \text { Min. }\end{array}$ & \begin{tabular}{|l|}
13,64 \\
13,36
\end{tabular} \mid & $-2,0$ & $\begin{array}{l}5,58 \\
4,16\end{array}$ & $-25,4$ & $\begin{array}{l}274 \\
183\end{array}$ & $-33,2 \mid$ & $\begin{array}{l}49,1 \\
44,0\end{array}$ & $-10,4$ & $\left|\begin{array}{l}13,64 \\
13,36\end{array}\right|$ & $-2,0$ & $\left|\begin{array}{l}5,88 \\
4,12\end{array}\right|$ & $-29,9$ \\
\hline 5 & $\begin{array}{c}2,00 \\
\hat{\delta}\end{array}$ & $\begin{array}{l}\text { Vord } \\
\text { phär } \\
\text { Nach }\end{array}$ & \begin{tabular}{|l|}
14,24 \\
14,24
\end{tabular} & \pm 0 & $\left|\begin{array}{l}5,25 \\
3,76\end{array}\right|$ & $-28,4$ & 157 & $-27,6$ & $\begin{array}{l}41,3 \\
41,7\end{array}$ & $+1,0$ & $\begin{array}{l}14,24 \\
14,24\end{array}$ & \pm 0 & $\left|\begin{array}{l}5,58 \\
3,61\end{array}\right|$ & $-35,3$ \\
\hline & $\begin{array}{l}\text { h- } \\
\text { itt }\end{array}$ & $\begin{array}{l}\text { Vor d. Plasma- } \\
\text { phäresis } \\
\text { Nach } 15 \text { Min. }\end{array}$ & $\begin{array}{l}14,29 \\
14,10\end{array}$ & $|-1,3|$ & $\begin{array}{l}5,38 \\
4,00\end{array}$ & $-25,7$ & $\begin{array}{l}202 \\
157\end{array}$ & $|-31,2|$ & $\begin{array}{l}42,9 \\
37,3\end{array}$ & $-8,3$ & $\begin{array}{l}14,29 \\
14,10\end{array} \mid$ & $-1,3$ & $\left|\begin{array}{l}\mathbf{a}, 60 \\
3,86\end{array}\right|$ & $|-31,2|$ \\
\hline
\end{tabular}


eiweisste Blut [welches in der Weise hergestellt wurde, dass man das zuvor einem gesunden Kaninchen entnommeńe Blut gleichen Quantums wie das durch den Aderlass verlorene durch Zentrifugieren vom Plasma befreite, dessen Blutzellen mit physiologischer Kochsalzlösung auswusch und diese ausgewaschee Erythrozyten mit gleicher Menge Normosallösung (steriles Serumsalz, Sächsisches Serumwerk A.-G., Dresden) durchmischte und auf die Körpertemperatur erwärmte] in die Ohrvene mit einer Geschwindigkeit von $10 \mathrm{ccm}$ in der Minute injiziert; 15 Minuten nach Beendigung der Injektion wurden aus drei Blutgefässen abermals je 1,7 ccm Blut entnommen. An diesen Blutproben wurden die Bestimmungen ausgeführt. Diesbezügliche Resultate sind in Tab. 5 wiedergegeben.

Die prozentische Abnahme des Hämoglobingehaltes nach Ausführung der Plasmaphäresis erwies sich in drei Blutarten als gleichgross. Die prozentische Abnahme des Eiweissgehaltes betrug im Lebervenenblut $25,7(28,4-22,9) \%$, im Pfortaderblut $31,2(35,3-25,5) \%$, im Carotisblut $31,1(35,7-25,9) \%$. Die prozentische Abnahme des k. o. D. betrug im Lebervenenblut $31,2(39,3-26,5) \%$, im Pfortaderblut 40,6 (46,6-34,6)\%, im Carotisblut 38,6 (47,5-33,1)\%. Dieselbe des Drucks pro \% betrug im Lebervenenblut $8,3(-18,3-+1,0) \%$,

$\overline{5}$.

venen-, Pfortader-sowie Carotisblutes nach Plasmaphäresis.

\begin{tabular}{|c|c|c|c|c|c|c|c|c|c|c|c|c|}
\hline \multicolumn{4}{|c|}{ V. portae } & \multicolumn{8}{|c|}{ A. carotis } & \multirow{3}{*}{ Bemerkungen } \\
\hline \multicolumn{2}{|c|}{ K. o. D. } & \multicolumn{2}{|c|}{$\begin{array}{c}\text { Druek pro } \\
\%\end{array}$} & \multicolumn{2}{|c|}{$\begin{array}{l}\text { Hämo- } \\
\text { globin }\end{array}$} & \multicolumn{2}{|c|}{$\begin{array}{l}\text { Serum- } \\
\text { eiweiss }\end{array}$} & \multicolumn{2}{|c|}{ K. o. D. } & \multicolumn{2}{|c|}{$\begin{array}{c}\text { Druck pro } \\
\%\end{array}$} & \\
\hline$\left(\begin{array}{l}\mathrm{mm} \\
\mathrm{H}_{2} \mathrm{O}\end{array}\right)$ & $\begin{array}{c}\text { Diff. } \\
\text { in } \%\end{array}$ & $\left(\begin{array}{l}\mathrm{mm} \\
\mathrm{H}_{2} \mathrm{O}\end{array}\right)$ & $\begin{array}{l}\text { Diffi. } \\
\text { in } \%\end{array}$ & $(g / \mathrm{dl})$ & $\begin{array}{l}\text { Diff. } \\
\text { in } \%\end{array}$ & $(\%)$ & $\begin{array}{l}\text { Ditf. } \\
\text { in } \%\end{array}$ & $\left(\begin{array}{l}\mathrm{mm} \\
\mathrm{H}_{2} \mathrm{O}\end{array}\right)$ & $\begin{array}{c}\text { Ditr. } \\
\text { in } \%\end{array}$ & $\left(\begin{array}{l}\operatorname{mim} \\
\mathrm{H}_{2} \mathrm{O}\end{array}\right)$ & $\begin{array}{l}\text { Diff. } \\
\text { in } \%\end{array}$ & \\
\hline 261 & & 45,9 & & 14,52 & & 5,58 & & 244 & & 43,7 & & Entnommene \\
\hline 154 & $-41,0$ & 39,8 & $-13,3$ & 13,64 & $-6,1$ & 3,72 & $-33,3$ & 128 & $-47,5$ & 34,4 & $\mid-21.2$ & Blutmenge $60 \mathrm{ccm}$. \\
\hline 198 & & 40,1 & & 14,24 & & 4,92 & & 199 & & 40,4 & & Entnommene \\
\hline 110 & $-44,4$ & 33,5 & $-16,4$ & 14,20 & $-0,3$ & 3,37 & $-31,5$ & 115 & $-42,2$ & 34,1 & $-15,5$ & Blutmenge $50 \mathrm{ccm}$. \\
\hline 257 & & 43,3 & & 14,80 & & 5,86 & & 242 & & 41,3 & & Entnommene \\
\hline 168 & $-34,6$ & 38,0 & $-12,2$ & 15,08 & $+1,9$ & 4,34 & -25.9 & 162 & $-33,1$ & 37,3 & $-9,7$ & Blutmenge $45 \mathrm{ccm}$. \\
\hline 294 & & 50,0 & & 13,64 & & $5,60 \mid$ & & 278 & & 49,6 & & Entnommene \\
\hline 181 & $-38,4$ & 43,9 & $-12,2$ & 13,36 & $-2,0 \mid$ & 4,01 & $-28,4$ & 176 & $-36,3$ & 43,9 & $-11,5$ & Blutmenge $55 \mathrm{ccm}$. \\
\hline 266 & & 47,7 & & 14,24 & & 5,56 & & 26.0 & & 46,8 & & Entnommene \\
\hline 142 & $-46,6$ & 39,3 & $-17,6$ & 14,24 & \pm 0 & 3,57 & $-35,7$ & 146 & $-43,8$ & 40,9 & $-12,6$ & Blutmenge $60 \mathrm{ccm}$. \\
\hline 255 & & 45,4 & & 14,29 & & 5,50 & & 245 & & 44,4 & & \\
\hline 151 & $-40,6$ & 38,9 & $-14,3$ & 14,10 & $-1,3$ & 3,80 & $-31,1$ & 125 & $-38,6$ & 36,1 & $-14,1$ & \\
\hline
\end{tabular}


im Pfortaderblut 14,3 (-17,6--12,2) \% und im Carotisblut 14,1 $(-21,2--9,7) \%$.

Wie aus obigem Ergebnisse ersichtlich ist, waren prozentische Abnahmen des Eiweissgehaltes, des k. o. D. und Drucks pro \% im Lebervenenblut ausserordentlich kleiner als dieselben in anderen zwei Blutarten. Besonders ausgeprägt trat dies beim Druck pro \% in den Vordergrund; während er nämlich z. B. im Versuch 5 im Pfortader- und Carotisblut gleich um 17,6 und 12,6\% herabgesetzt war, erhöhte er sich im Lebervenenblut überraschenderweise ja um $1,0 \%$. Hieraus erhellt, dass die Leber ihr Reserveeiweiss, vornehmlich osmotisch aktive kleinmolekuläre Eiweissteilchen in das Blut mobilisiert, damit sie den Organismus gegen den Eiweissmangel und die dadurch zu verursachende Erniedrigung des k.o.D. zu schützen anstrebt.

Oben beschriebene Resultate seien im folgenden nochmals zusammenfassend betrachtet. Das im physiologischen Zustande aus der Leber ausströmende Lebervenenblut enthält weniger konzentriertes Eiweiss, als dem in die Leber einströmenden Pfortaderblut entspricht, und diese Differenz im Eiweissgehalt rührt davon her, dass ein Teil der vom Verdauungstraktus her transportierten Eiweisskörper in der Leber aufbewahrt wird; es ist offenbar ein Beweis dafür, dass die Leber der Vorratsort der Eiweisskörper ist. Der Umstand, dass der Druck pro \% des Lebervenenblutes niedriger als der des Pfortaderund Carotisblutes ist, deutet zweifellos darauf hin, dass das von der Leber sonst abzugebende Eiweiss relativ grobmolekulärer Natur ist.

Indessen erweist sich der Druck pro \% des Lebervenenblutes dort, wo wiederholte Blutentziehungen vorgenommen worden sind, als höher denn der des Pfortader- und Carotisblutes. Dies ist darauf zurückzuführen, dass die Leber hierbei relativ kleinmolekuläre Eiweissteilchen an die Blutbahn abgibt und somit der Wiederherstellung des k.o.D. zustrebt.

Des weiteren bin ich zur U̇berzeugung gelangt, dass, wenn auf dem Wege der Aderlässe oder der Plasmaphäresis Eiweissverluste des Blutes bewirkt worden sind, die Leber sofort darauf anspricht und ihr Depoteiweiss in die Lebervene mobilisiert, wobei sie vornehmlich kleinmolekuläre Eiweissteilchen unverzüglich abgibt und auf solche Weise am Vorgang der Wiederherstellung des k. o. D. des Blutes dominierend teilnimmt. 


\section{Schluss.}

1. Bei normalen Kaninchen zeigen der Eiweissgehalt und der kolloid-osmotische Druck sowie Druck pro \% Eiweiss aus der Leber ausströmenden Lebervenenblutes gemeinschaftlich niedrigere Werte als entsprechende Grössen des Pfortader- und Carotisblutes.

2. Der Druck pro \% des Blutes, welches aus der Leber des normalen Kaninchens, bei welchem durch wiederholte Blutentnahmen allmählich Anämie erzeugt worden ist, ausströmt, erweist sich stets als höher denn der des Pfortader- und Carotisblutes.

3. Wenn bei normalen Kaninchen durch einmalige Entnahme der kleineren oder grösseren Blutmengen oder durch Ausführung der Plasmaphäresis akute Verluste des Bluteiweisses herbeigeführt worden sind, dann weisen der Eiweissgehalt, der kolloid-osmotische Druck sowie Druck pro \% des der Leber entströmenden Blutes nicht allein höhere Werte als dieselben des Pfortader- und Carotisblutes auf, sondern sie können mitunter und sogar über die Werte vor dem Aderlasse hin aussteigen. 